\title{
A Mind-Body Problem? A Reply to Lisa Taylor's Article "Canadian Culture," Cultural Difference, and ESL Pedagogy
}

Robert Courchêne

I would first like to thank Lisa Taylor for joining this debate. In her excellent article she has clarified a number of issues and, as any good author does, raised a number of important questions. In this short response I would like to comment on the distinction she makes between cultural diversity and cultural difference after Bhabha (1995).

Taylor points out that with my insistence on the importance of knowledge in the teaching of cultural (and, I believe, being a member of a cultural community) I represent the cultural diversity position. Although this may be true, what bothers me more is that we will end up seeing these two categories much like the mind-body problem in philosophy. For me the two are not separate; they are overlapping, mutually supporting positions.

When new Canadians arrive in Canada, their point of reference is their own culture-a dynamic force that has shaped their lives since birth, an amalgam of experience and knowledge (see Figure 1, Schein, 1985, p. 22). They may have little or no knowledge of the traditions and ritual, history, stories and myths, heroes and heroines, behavioral norms, or values and beliefs of their new culture. For example, when I was first invited to the home of a Chinese friend, I wanted to bring a gift, but did not know what to bring. In my own culture, wine, flowers, chocolate, and so forth would have been acceptable. I was told that coffee, imported food, or watermelon (in the middle of winter) would be greatly appreciated. In this case and many others, my cultural learning started with knowledge and slowly became transformed into understanding: watermelons are expensive in the winter, and most of the families could not afford them; in summer they are found everywhere in the streets and are, therefore, cheap. In talking about cultural diversity and cultural difference, it is important to realize that these are not mutually exclusive concepts. The journey for new Canadians toward cultural integration in our society (if that is what they want) is a progression that in many cases begins with learning about Canadian history, beliefs, traditions, and so forth. When newcomers do learn about them, they naturally contrast them with their own culture (knowledge and experience). If they decide to integrate certain aspects of their new culture into their existing (dynamic) cultural vision, it will result in changes. 

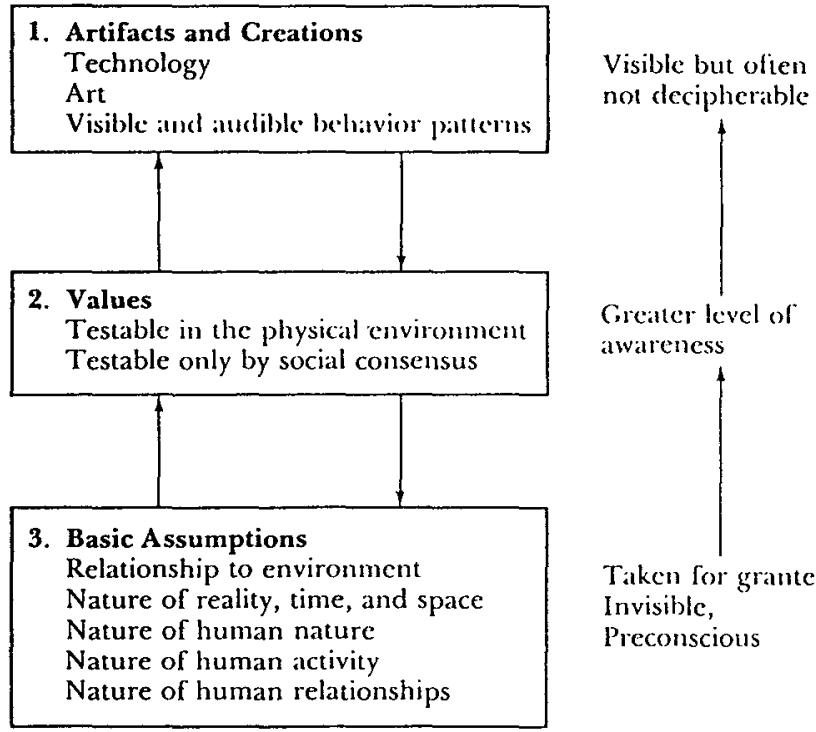

Greater level of awareness

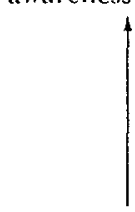

Taken for granted, Invisible,

Preconscious

Figure 1. The levels of culture.

If one looks at Schein's (1985) visual display of different aspects of culture, it is evident that just telling people about basic assumptions that underlie Canadian society will not enable them to internalize them; that is, our relationship toward nature or our concept of time. These values cannot be taught the same way the names of prime ministers of Canada can. In many cases teachers would have great difficulty in even describing them; such values must be lived and experienced in context; teachers may be able, however, to create situations inside and outside class to place students in situations that will allow them to gain some insight into what makes Canadians tick. Trying to teach Canadian culture at this level, therefore, is the real challenge, as traditional transmission methods do not work.

In talking about the relationship between knowledge and experience, about culture as an "epistemological object" and culture as coming to be "knowable and known and what relations they establish between knowers" (Bhabha, 1995, pp. 206-207), one must distinguish between the entry level of cultural experience and a more fully developed cultural experience. Although the door leading in may be knowledge, the road that leads to real cultural understanding is certainly that of experience. However, it often happens that as people become detached from their culture, that is, they no longer have experiential knowledge, they do things on the basis of knowledge or tradition without really knowing why they are doing it. The relation between the two, therefore, is often complex. At a Pow-Wow to celebrate Aboriginal culture, I overheard two young people talking. One asked why the sweetgrass ceremony is carried out at the beginning of certain events. The 
other answered, "I don't know; something about the earth is all I remember my grandfather telling me." He went on, however, to explain in detail how it was done. Here we have a case of memory without the underlying cultural values and beliefs.

In other cases new Canadians often acquire experiential knowledge (often through episodic learning) without at the same time knowing why what happened happened, for example, people who were yelled at for cutting into lines, who are told it is not polite to swear (native speakers accord themselves this privilege), or who are constantly refused jobs or apartments. When they are told about certain cultural traditions or power relationships, they come to understand, although they do not necessarily accept or agree with what happened.

In summary, knowledge and experience are intertwined parts of any dynamic culture. At different times in an individual's personal journey toward increased cultural understanding or cultural integration, one or other of the two components may play an important role. Furthermore, some aspects of culture are easier to present in a didactic manner, whereas others must be experienced to be understood. Our challenge as teachers is to set up learning environments both inside and outside of the classroom that will enable new Canadians to experience all aspects of our culture so they can arrive at a new cultural dynamic that will allow them to function comfortably (culturally speaking) in our society.

\section{References}

Bhabha, H. (1995). Cultural diversity and cultural differences. In B. Ashcroft, G. Griffiths, \& H. Tiffin (Eds.), The post-colonial studies reader (pp. 206-211). London: Routledge.

Schein, E. (1985). How culture forms, develops and changes. In R. Kilman, M. Saxton, R. Serpa, \& Associates (Eds.), Gaining control of the corporate culture (pp. 17-43). San Francisco, CA: Jossey-Bass.

\section{Editor's Note}

Both Robert Courchêne and Virginia Sauvé were invited to respond to Lisa Taylor's article. Dr. Sauvé regrets that she was unable to do so, for reasons not associated with the article. 